\title{
Perception of Saudi Undergraduate Students Towards Professionalism in Medicine
}

\author{
Suzan A. AlKhater
}

\begin{abstract}
Objectives: Professionalism has garnered immense attention in medical education due to increased societal accountability and focus on excellence in healthcare. However, less attention has been given to identifying attitudes about professionalism in medical students who are the future advocates of the healthcare system. This study aimed to assess perceptions of Saudi undergraduate medical students towards professionalism. Methods: A crosssectional survey was carried out among second and sixth year students of the College of Medicine, Imam Abdulrahman Bin Faisal University, Dammam, Saudi Arabia, in September 2018. A self-administered professionalism questionnaire was anonymously completed. Students were asked to provide their level of agreement with 18 survey items using a 5-point Likert scale. Results: Overall, 288 students participated in the study (males: 49.3\% and females: 50.7\%), with a response rate of $90 \%$. The median professionalism score was high (71.0; range: 64-76) regardless of age, gender or level of education. Similar high scores were noted in the following subscales: Excellence, 20.0 (range: 18-21); Respect for Others, 17.0 (14-18); Altruism, 12.0 (10-13); Duty, 8.0 (7-9); Accountability, 7.0 (6-8) and Honour and Integrity, $8.0(7-10)$. No gender differences were observed in the majority of subscales. However, males demonstrated higher scores in the Duty subscale (males: 9.0 versus females: 8.0; $P=0.026$ ). Conclusion: Medical students demonstrated high professionalism scores. Future studies are needed to assess the impact of the course curriculum on their level of professionalism over time.
\end{abstract}

Keywords: Attitudes; Curriculum; Medical Students; Professionalism; Survey; Saudi Arabia.

\section{ADVANCES IN KNOWLEDGE}

The current literature shows an increased focus on medical professionalism in various contexts due to the positive impact of professional performance on the healthcare provided.

The findings of this study reveal how undergraduate medical students at a Saudi university perceive professionalism.

\section{Application to Patient Care}

The study can help raise awareness of the significance of professionalism among students, faculty and the administration of medical universities.

Increased focus on teaching strategies on medical professionalism to medical graduates could contribute to their future success.

Implementing the learned attributes of professionalism during medical students' undergraduate years could contribute to their future success and positively influence the quality of healthcare services provided.

$\mathrm{I}$ RECENT YEARS, THE TOPIC OF PROFESSIONALISM has been in the spotlight as a mechanism for improving healthcare standards. The increased focus on professionalism in medicine can be attributed to increased demands for optimal performance by physicians, societal accountability and continuous professional development of medical students and trainees. ${ }^{1}$ One important area of development is the continuing emphasis on empathy toward the patient, which several studies have shown may suffer, if efforts are not undertaken during training to maintain proper attitudes and values. ${ }^{2}$ The medical school years provide the foundation during which lifelong professional standards are initiated and potentially established. The years that one spends as an undergraduate medical student represent a critical period that shapes future doctors.
Depending on a school's vision for teaching professionalism, students are taught the art of professionalism either via principles integrated into their curriculum or by establishing a model of behaviour for these future doctors. In fact, studies have shown that medical students primarily learn professional values by following their role models through a 'hidden curriculum.' This phenomenon is now well described in the literature as professional identity formation. ${ }^{4}$

Although the best means of implementing the learned attributes of professionalism during undergraduate training remain uncertain, it is clear that integrating professionalism into the curriculum can positively influence the quality of healthcare provided. ${ }^{5,6}$ Due to the positive impact of professional performance by healthcare providers, the current 
literature shows an increased focus on medical professionalism in various contexts. As a result, many studies tend to present various teaching strategies that medical educators can implement in undergraduate medical school curricula to impart professionalism to students. ${ }^{6-8}$ Having recognised the value of teaching the art and science of professionalism to undergraduates and trainees, scholars have urged institutions to assess the attitudes of students and graduates towards professionalism and to measure the efficacy of the strategies implemented in the curriculum. ${ }^{9}$ However, these observations are difficult to generalise, primarily because the techniques used to teach professionalism vary widely. ${ }^{6,10}$ What complicates matters even further is the absence of a universally agreed-upon definition of the term 'professionalism' and the qualities or values that it constitutes. ${ }^{10-12}$ To address the variations in teaching methods and changes in curriculum development, diverse assessment tools are essential for evaluating the professionalism of recent medical graduates who have participated in new educational strategies. ${ }^{9}$

The undergraduate medical curriculum in Saudi Arabia has recently undergone a major shift from a traditional teacher-centred model to a self-directed learning model in which the student is the focus of attention, with the teacher merely acting as a facilitator of the learning process. ${ }^{13}$ This paradigm shift in learning strategy can result in different trends, attitudes and perceptions about professionalism that must be addressed according to the needs of the environment, including cultural demands, if any. A report on how medical professionals from Arabic countries view the concept of professionalism in an Arabian context acknowledged the existence of cultural differences that emphasise the need to add domains that address faith, values and history to the existing six domains of the American Board of Internal Medicine (ABIM) framework of professionalism, which include 'altruism', 'accountability', 'excellence,' 'honour and integrity', 'duty' and 'respect.'. ${ }^{4,15}$ Western literature assessing students' attitudes towards professionalism is rich; however, there are few studies in the Arab world. ${ }^{14,16}$ Measuring the attitudes of medical students towards professionalism becomes particularly important as institutes and national accreditation boards place increased emphasis on professionalism in medical practice. ${ }^{17}$ This study aimed to assess the perceptions of Saudi undergraduate medical students towards professionalism in a single university and to compare levels of professionalism according to age, gender and level of education.

\section{Methods}

This cross-sectional study was conducted at the College of Medicine, Imam Abdulrahman Bin Faisal University, Dammam, Saudi Arabia, in September 2018. The study invited all medical students enrolled in their second and sixth year (final year) of the Bachelor of Medicine and Surgery (MBBS) programme to participate $(\mathrm{N}=320)$. To ensure that the call for participation in the study reached the maximum number of students, the invitation was made in the students' respective classrooms on the first day of classes and during the opening of new courses.

Instruction to students was provided by the researcher. Information about the purpose of the

Table 1: Items of the self-administered professionalism instrument developed by Chisholm et al. administered to second- and sixth-year students enrolled in the College of Medicine, Imam Abdulrahman Bin Faisal University, Dammam, Saudi Arabia ${ }^{18}$

1 I do not expect anything in return when I help someone.

2 I attend class/clerkship/work daily.

3 If I realize that I will be late, I contact the appropriate individual at the earliest possible time to inform them.

4. If I do not follow through with my responsibilities, I readily accept the consequences.

5 I want to exceed the expectations of others.

6 It is important to produce quality work.

7 I complete my assignments independently and without supervision.

8 I follow through with my responsibilities.

9 I am committed to helping others.

10 I would take a job where I felt I was needed and could make a difference even if it paid less than other positions.

11 It is wrong to cheat to achieve higher rewards (i.e. grade or money).

12 I would report a medication error even if no one else was aware of the mistake.

13 I am able to accept constructive criticism.

14. I treat all patients with the same respect, regardless of perceived social standing or ability to pay.

15 I address others using appropriate titles and names.

16 I am diplomatic when expressing ideas and opinion.

17 I accept decisions of those in authority.

18 I am respectful to individuals who have different backgrounds than mine.

Tenets: Excellence (items 2, 5, 7, 8, 17), Respect for Others (items 14, 15, 16, 18), Altruism (item 1, 9, 10), Duty (items 6, 13), Accountability (items 3, 4), Honour and Integrity (items 11, 12). 


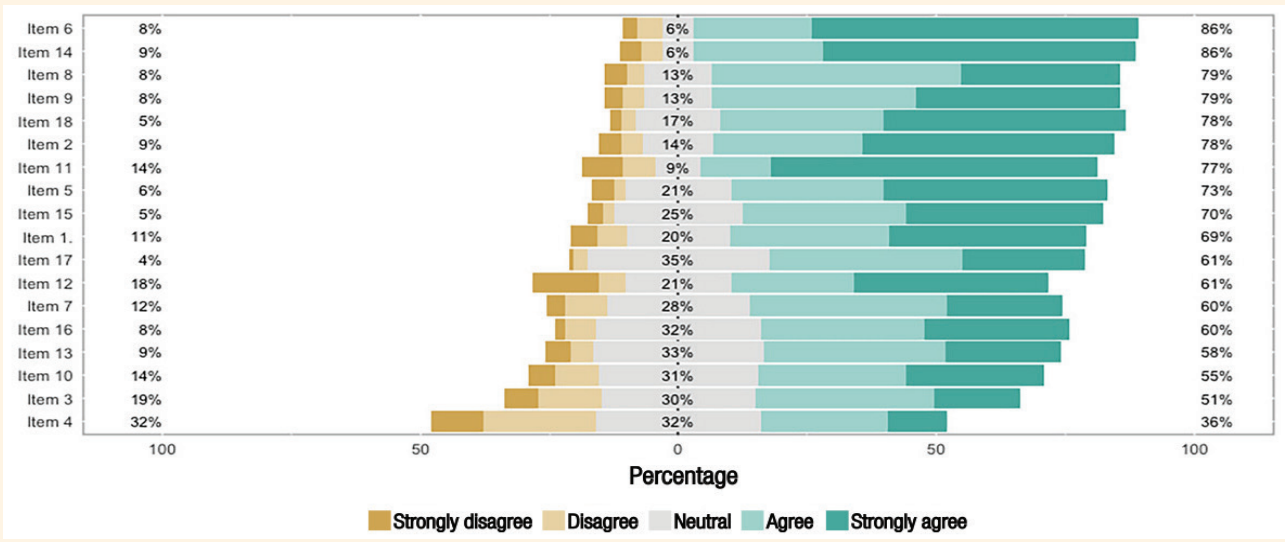

Figure 1: The responses of 139 second-year students from the College of Medicine, Imam Abdulrahman Bin Faisal University, Dammam, Saudi Arabia, to items on the professionalism instrument.

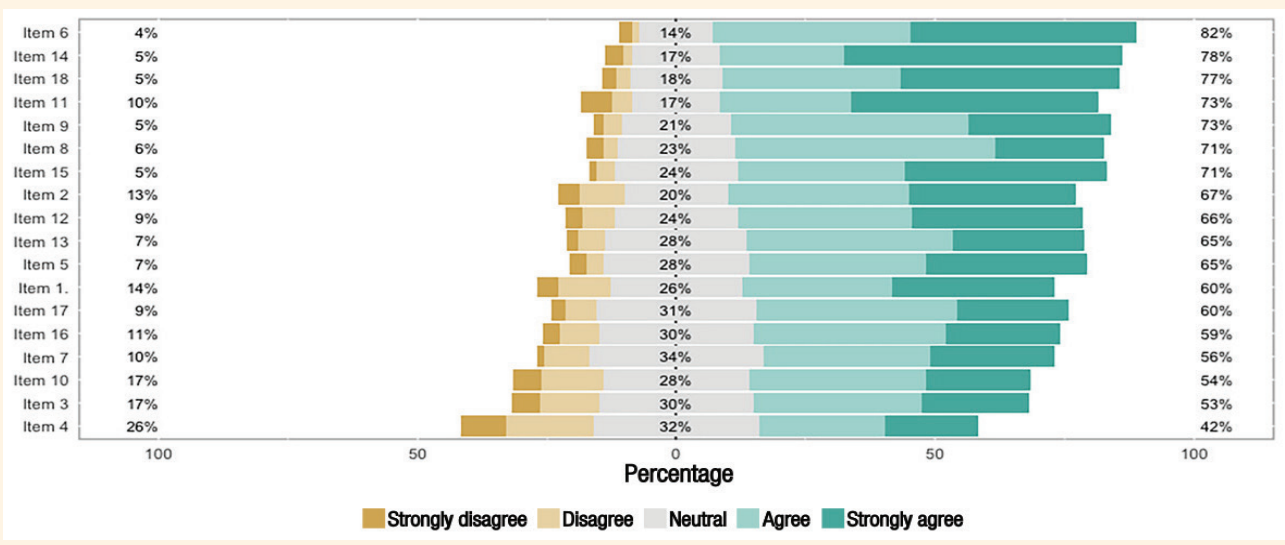

Figure 2: The responses of 149 sixth-year students from the College of Medicine, Imam Abdulrahman Bin Faisal University, Dammam, Saudi Arabia, to items on the professionalism instrument.

study, a description of the questionnaire and disclosure of the privacy policy were provided. The researcher explained to students that their participation was entirely voluntary and that participants could opt out of the study at any time. After instructions were given and informed written consent to participate in the study was obtained, the students were asked to complete the survey anonymously and confidentially. Even if the students were working in the same class, they were expected to respond without discussing the items on the questionnaires with other students; thus, they were not aware of the other participants' answers. This single-blind communication was practiced throughout the survey to ensure the individuality of the responses. The identity of the participants was not revealed to the investigators conducting the survey or during the analysis. Questionnaires were collected on the same day they were distributed.

The questionnaire used was a self-administered tool developed by Chisholm et al. to assess professionalism that was later validated and found reliable when used to assess pharmacy and medical students. ${ }^{18-22}$ The professionalism instrument consists of a questionnaire that includes 18 statements (items) that measure the ABIM's six tenets of professionalism. Participants responded to each item using a 5-point Likert scale with a corresponding scoring system consisting of the following responses: 'strongly disagree' (1), 'disagree' (2), 'neutral' (3), 'agree' (4) and 'strongly agree' (5). Therefore, the higher the rating on the scale, the higher the level of professionalism [Table 1].

The questionnaire was written in English and was manually distributed. Demographic information on gender, age and year of study was also requested. Prior to utilisation, the scale items were reviewed for clarity, comprehensiveness and content validity by the investigators and senior faculty members. The instrument was also pretested in a pilot study to check the students' responses and assess the clarity and suitability of the items. This pilot study was performed on five females and five males who were randomly selected from second- and sixth-year classes. The students answered the items with ease; therefore no adjustments were required and their responses were added to the dataset. 
Table 2: Comparison of the professionalism scale and subscale scores across age groups according to the American Board of Internal Medicine's tenets of professionalism $(\mathrm{N}=288)$

\begin{tabular}{|c|c|c|c|c|}
\hline $\begin{array}{l}\text { Scale/Subscale } \\
\text { (Min, Max) }\end{array}$ & $\begin{array}{c}\text { Overall } \\
\text { median } \\
(\mathrm{IQR})\end{array}$ & $\begin{array}{c}<20 \\
\text { years } \\
\text { median } \\
(\text { IQR) }\end{array}$ & $\begin{array}{c}20-30 \\
\text { years } \\
\text { median } \\
(\text { IQR })\end{array}$ & $\begin{array}{c}P \\
\text { value }^{*}\end{array}$ \\
\hline $\begin{array}{l}\text { Professionalism } \\
(18,90)\end{array}$ & $\begin{array}{c}71.0 \\
(64-76)\end{array}$ & $\begin{array}{c}73.0 \\
(64-79)\end{array}$ & $\begin{array}{c}70.0 \\
(65-75)\end{array}$ & 0.094 \\
\hline \multicolumn{5}{|c|}{ Subscale scores } \\
\hline $\begin{array}{l}\text { Excellence } \\
(5,25)\end{array}$ & $\begin{array}{c}20.0 \\
(18-21)\end{array}$ & $\begin{array}{c}20.0 \\
(17-22)\end{array}$ & $\begin{array}{c}19.0 \\
(18-21)\end{array}$ & 0.077 \\
\hline $\begin{array}{l}\text { Respect for } \\
\text { Others }(4,20)\end{array}$ & $\begin{array}{c}17.0 \\
(14-18)\end{array}$ & $\begin{array}{c}17.0 \\
(15-19)\end{array}$ & $\begin{array}{c}16.0 \\
(14-18)\end{array}$ & 0.311 \\
\hline Altruism $(3,15)$ & $\begin{array}{c}12.0 \\
(10-13)\end{array}$ & $\begin{array}{c}12.0 \\
(11-13)\end{array}$ & $\begin{array}{c}11.5 \\
(10-13)\end{array}$ & 0.013 \\
\hline Duty $(2,10)$ & $\begin{array}{c}8.0 \\
(7-9)\end{array}$ & $\begin{array}{c}8.5 \\
(7-9)\end{array}$ & $\begin{array}{c}8.0 \\
(7-9)\end{array}$ & 0.424 \\
\hline $\begin{array}{l}\text { Accountability } \\
(2,10)\end{array}$ & $\begin{array}{c}7.0 \\
(6-8)\end{array}$ & $\begin{array}{c}6.0 \\
(5-7)\end{array}$ & $\begin{array}{c}7.0 \\
(6-8)\end{array}$ & 0.035 \\
\hline $\begin{array}{l}\text { Honour and } \\
\text { Integrity }(2,10)\end{array}$ & $\begin{array}{c}8.0 \\
(7-10)\end{array}$ & $\begin{array}{c}9.0 \\
(6-10)\end{array}$ & $\begin{array}{c}8.0 \\
(7-9)\end{array}$ & 0.644 \\
\hline
\end{tabular}

Table 3: Comparison of the professionalism scale and subscale scores by gender according to the American Board of Internal Medicine's tenets of professionalism $(\mathrm{N}=288)$

\begin{tabular}{|c|c|c|c|c|}
\hline $\begin{array}{l}\text { Scale/Subscale } \\
\text { (Min, Max) }\end{array}$ & $\begin{array}{c}\text { Overall } \\
\text { median } \\
(\mathrm{IQR})\end{array}$ & $\begin{array}{c}\text { Median } \\
\text { for } \\
\text { Males } \\
\text { (IQR) }\end{array}$ & $\begin{array}{c}\text { Median } \\
\text { for } \\
\text { Females } \\
\text { (IQR) }\end{array}$ & $\begin{array}{c}P \\
\text { value }^{*}\end{array}$ \\
\hline $\begin{array}{l}\text { Professionalism } \\
(18,90)\end{array}$ & $\begin{array}{c}71.0 \\
(64-76)\end{array}$ & $\begin{array}{c}70.5 \\
(64-76)\end{array}$ & $\begin{array}{c}71.0 \\
(66-77)\end{array}$ & 0.330 \\
\hline \multicolumn{5}{|c|}{ Subscale scores } \\
\hline $\begin{array}{l}\text { Excellence } \\
(5,25)\end{array}$ & $\begin{array}{c}20.0 \\
(18-21)\end{array}$ & $\begin{array}{c}19.0 \\
(17-21)\end{array}$ & $\begin{array}{c}20.0 \\
(18-22)\end{array}$ & 0.091 \\
\hline $\begin{array}{l}\text { Respect for } \\
\text { Others }(4,20)\end{array}$ & $\begin{array}{c}17.0 \\
(14-18)\end{array}$ & $\begin{array}{c}16.0 \\
(14-18)\end{array}$ & $\begin{array}{c}17.0 \\
(15-18)\end{array}$ & 0.183 \\
\hline Altruism $(3,15)$ & $\begin{array}{c}12.0 \\
(10-13)\end{array}$ & $\begin{array}{c}12.0 \\
(10-13)\end{array}$ & $\begin{array}{c}12.0 \\
(10-13)\end{array}$ & 0.585 \\
\hline Duty $(2,10)$ & $\begin{array}{c}8.0 \\
(7-9)\end{array}$ & $\begin{array}{c}9.0 \\
(7-9)\end{array}$ & $\begin{array}{c}8.0 \\
(7-9)\end{array}$ & 0.026 \\
\hline $\begin{array}{l}\text { Accountability } \\
(2,10)\end{array}$ & $\begin{array}{c}7.0 \\
(6-8)\end{array}$ & $\begin{array}{c}6.0 \\
(5-8)\end{array}$ & $\begin{array}{c}7.0 \\
(6-8)\end{array}$ & 0.374 \\
\hline $\begin{array}{l}\text { Honour and } \\
\text { Integrity }(2,10)\end{array}$ & $\begin{array}{c}8.0 \\
(7-10)\end{array}$ & $\begin{array}{c}8.0 \\
(6-9)\end{array}$ & $\begin{array}{c}8.0 \\
(7-10)\end{array}$ & 0.097 \\
\hline
\end{tabular}

Min, Max = minimum, maximum score; $I Q R=$ interquartile range

"Pvalues based on the Mann-Whitney U test.

Sample size was addressed by the authors of a systematic review of tools for assessing professionalism in pharmacy practice (which included the tool developed by Chisholm et al). ${ }^{23}$ The researchers determined that a sample size of 150 was sufficient but more than 300
Table 4: Comparison of the professionalism scale and subscale scores across educational level according to the American Board of Internal Medicine's tenets of professionalism ( $\mathrm{N}=288)$

\begin{tabular}{|c|c|c|c|c|}
\hline $\begin{array}{l}\text { Scale/Subscale } \\
\text { (Min, Max) }\end{array}$ & $\begin{array}{c}\text { Overall } \\
\text { median } \\
(\mathrm{IQR})\end{array}$ & $\begin{array}{l}\text { Second } \\
\text { year } \\
\text { Median } \\
\text { (IQR) }\end{array}$ & $\begin{array}{c}\text { Sixth } \\
\text { year } \\
\text { Median } \\
\text { (IQR) }\end{array}$ & $\begin{array}{l}P \\
\text { value* }\end{array}$ \\
\hline $\begin{array}{l}\text { Professionalism } \\
(18,90)\end{array}$ & $\begin{array}{c}71.0 \\
(64-76)\end{array}$ & $\begin{array}{c}72.0 \\
(65-77)\end{array}$ & $\begin{array}{c}70.0 \\
(64-75)\end{array}$ & 0.105 \\
\hline \multicolumn{5}{|l|}{ Subscale scores } \\
\hline $\begin{array}{l}\text { Excellence } \\
(5,25)\end{array}$ & $\begin{array}{c}20.0 \\
(18,-21)\end{array}$ & $\begin{array}{c}20.0 \\
(18-22)\end{array}$ & $\begin{array}{c}19.0 \\
(17-21)\end{array}$ & 0.016 \\
\hline $\begin{array}{l}\text { Respect for } \\
\text { Others }(4,20)\end{array}$ & $\begin{array}{c}17.0 \\
(14-18)\end{array}$ & $\begin{array}{c}17.0 \\
(15-19)\end{array}$ & $\begin{array}{c}17.0 \\
(14-18)\end{array}$ & 0.529 \\
\hline Altruism $(3,15)$ & $\begin{array}{c}12.0 \\
(10-13)\end{array}$ & $\begin{array}{c}12.0 \\
(10-13)\end{array}$ & $\begin{array}{c}11.0 \\
(10-13)\end{array}$ & 0.033 \\
\hline Duty $(2,10)$ & $\begin{array}{c}8.0 \\
(7-9)\end{array}$ & $\begin{array}{c}8.0 \\
(7-9)\end{array}$ & $\begin{array}{c}8.0 \\
(7-9)\end{array}$ & 0.592 \\
\hline $\begin{array}{l}\text { Accountability } \\
(2,10)\end{array}$ & $\begin{array}{c}7.0 \\
(6-8)\end{array}$ & $\begin{array}{c}7.0 \\
(5-7)\end{array}$ & $\begin{array}{c}7.0 \\
(6-8)\end{array}$ & 0.203 \\
\hline $\begin{array}{l}\text { Honour and } \\
\text { Integrity }(2,10)\end{array}$ & $\begin{array}{c}8.0 \\
(7-10)\end{array}$ & $\begin{array}{c}9.0 \\
(6-10)\end{array}$ & $\begin{array}{c}8.0 \\
(7-9)\end{array}$ & 0.501 \\
\hline
\end{tabular}

Min, Max = minimum, maximum score

"P values based on the Mann-Whitney $U$ test; $I Q R=$ interquartile range.

was desirable. The four studies considered eligible for review in the analysis ranged in size from 231 to 1,202. Thus, for the current study, the sample size of 288 was deemed to be more than sufficient. A composite score for the entire professionalism scale and scores for the various subscales (tenets) were computed; the higher the score, the greater the level of professionalism associated with the student.

Demographic data are presented as numbers and frequencies. Student responses to the professionalism instrument were normally distributed according to the Kolmogorov-Smirnov test and the Shapiro-Wilk's test. Hence the scores are reported as median and interquartile range in the tables.

Cronbach's alpha coefficient was used to estimate the internal consistency of the assessment. Since the total scores on the professionalism scale and subscales were not normally distributed, they are reported as medians and ranges (minimum, maximum) and the comparisons by age groups, gender and educational level were analysed by the Mann-Whitney $U$ test. The level of significance was set at $P<0.05$. The data were analysed using Statistical Package for the Social Sciences (SPSS), Version 24.0 (IBM Corp., Armonk, New York, USA). The graphs were made using the $\mathrm{R}$ package Likert, Version 1.3.5 (R Foundation for Statistical Computing, Vienna, Austria).

Written informed consent was obtained from the participants. The study received ethical approval from the Institutional Review Board. 


\section{Results}

Of the 320 questionnaires distributed, 288 students responded (response rate: 90\%). The participants included 139 second-year students (males: 66 [47.5\%] and females: 73 [52.5\%]) and 149 sixth-year students (males: 76 [51\%] and females: 73 [49\%]). The age of the participants ranged from 19 to 30 years. For the analysis, the age group of the participants was divided into two categories, $<20$ and $20-30$ years old. A total of $90(64.7 \%)$ second-year students were aged $<20$ years of age and 149 (100\%) sixth-year students were 20-30 years old. The reliability analysis of the professionalism scale and subscales showed that Cronbach's alpha values for the professionalism scale were 0.904 for second-year students and 0.873 for sixth-year students, indicating high reliability of the instrument within each class. The 'Excellence,' 'Respect for Others' and 'Altruism' subscales had acceptable Cronbach's alpha values. However, 'Duty', 'Honour and Integrity', and 'Accountability' subscales had poor Cronbach's alpha values $(<0.6)$; therefore, the findings of these subscales need to be interpreted with caution.

The majority of the second-year and sixthyear students either agreed or strongly agreed with the statements on the professionalism instrument, indicating the likelihood of a high level of professionalism in both groups [Figures 1 and 2].

The overall median score on the professionalism scale was 71.0 (range: 64-76); this score was higher in students who were $>20$ years old than it was in older participants, but the difference did not reach statistical significance (73.0 versus 70.0; $P=0.094$ ). The difference in scores for the 'Excellence,' 'Respect for Others, 'Duty and Honour' and 'Integrity' subscales according to the age group of the participants, was not statistically significant. However, in the 'Altruism' subscale, the score was significantly higher among younger students than older students (12.0 versus $11.5 ; P=0.013)$. In the 'Accountability' subscale, the score was higher among older students than younger students (7.0 versus 6.0; $P=0.035)$ [Table 2].

The median score on the professionalism scale according to gender was 71.0 for females and 70.5 for males $(P=0.330)$. The scores for 'Excellence,' 'Respect for Others', 'Altruism,' 'Accountability' and 'Honour and Integrity', though visibly different across multiple subscales, did not differ significantly according to gender. However, in the 'Duty' subscale, the score was significantly higher among males than females (9.0 versus 8.0; $P=0.026$ ) [Table 3].

The median score on the professionalism scale according to the students' level of education was 72.0 for second-year and 70.0 for sixth-year students $(P=0.105)$. The scores for the 'Respect for Others',
'Duty', 'Accountability' and 'Honour and Integrity' subscales did not yield a statically significant difference according to the students' level of education. However, the scores were significantly higher among second-year students than sixth-year students in the 'Excellence' (20.0 vs. 19.0; $P=0.016$ ) and 'Altruism' (12.0 versus 11.0; $P=0.033)$ subscales [Table 4].

\section{Discussion}

The initiation and development of optimal professional behaviours among medical students are becoming increasinglynecessary. Therefore, theSaudiMED framework recognises professionalism as one of the six competencies required by Saudi medical graduates. ${ }^{24}$ These tenets include a scientific approach to practice, patient care, community-orientedpractice, communication and collaboration, professionalism and research and scholarship. Essential methods for promoting professionalism include creating an educational environment that promotes the development of positive attitudes towards professionalism among undergraduate medical students. ${ }^{24}$ Professionalism among medical graduates can be ensured only if sincere efforts are made to effectively measure it using reliable instruments. Therefore, perfecting tools to measure professionalism has been a focus in recent years. ${ }^{25}$

In this study, students from two specific time points in the MBBS programme were studied: the second- and sixth-years. Students in their second year of medical school were selected because this year represents the students' first encounter with the medical curriculum. The first year of the programme is a preparatory year and represents the influence of general education on the student before joining the medical school programme. The other group comprised sixth-year (final year) students of the medical college who have experienced the entirety of the MBBS curriculum. This latter group represents the influence of the medical school programme on the students' perception of professionalism. These two levels of study were selected to compare the two ends of the medical education curriculum and measure attitudes across undergraduate medical education.

Among the students surveyed, the median professionalism score was high. This finding is consistent with previous studies, which showed that medical students had above-average professionalism scores or high knowledge of professionalism..$^{20,26}$ However, the findings in our study differ from those of other studies, which reported that medical students had unfavourable levels of professionalism and inadequate theoretical knowledge about professionalism..$^{27,28}$ Furthermore, it was found that, overall, the professionalism score was 
slightly higher among younger students than older students. The difference, however, was not statistically significant.

Previous studies have noted a decline in professionalism scores as students advance through their clinical clerkship. ${ }^{27}$ Compared with sixth-year students, the second-year students in the current study had significantly higher scores on the 'Altruism' and 'Excellence' subscales. Altruism, which is the essence of professionalism, emphasises the best interest of patients and not self-interest. ${ }^{15}$ The reason for this observation was not clear, but a similar observation was made by Bhutto et al., who found that preclinical students had higher scores than clinical students on the 'Altruism' subscale. ${ }^{20}$ Additionally, in the current study, second-year students had significantly higher scores compared with sixth-year students on the 'Excellence' subscale, which entails a conscientious effort to exceed ordinary expectations and make a commitment to life-long learning. It is likely that as sixth-year students approach graduation, they tend to be overwhelmed with the stress of clinical clerkships and specific marking schemes of medical schools that do not emphasise excellence. However, this idea contrasts with the finding of a previous study showing that clinical students had a higher level of excellence than preclinical students. ${ }^{20}$

In the current study, no gender differences in the level of professionalism were found, a finding consistent with the results of previous studies. ${ }^{20,27,28}$ This suggests that the approaches used in delivering training on professionalism among the students appear to be gender-neutral. In addition, there were no differences in most of the subscale scores according to gender. However, compared to females, male students had significantly higher scores in the 'duty' subscale, which deals with the free acceptance of a commitment to service. The difference may be due to different gender roles in the setting due to cultural or religious reasons. Future studies need to explore the potential reasons for gender differences in this subscale.

Although there were no differences in scores according to age groups, there were differences in subscale scores for 'Altruism' and 'Accountability'. Compared to students who were 20-30 years old, younger students had a significantly higher score on the 'Altruism' subscale. The reason for this observation is not clear. Furthermore, it was found that students $<20$ years of age had significantly lower scores on the 'Accountability' subscale, which requires that physicians are accountable to their patients, society and their profession. ${ }^{15}$ Perhaps this is due to older students being more likely to be mature and have more experience in being held accountable for their actions.
This study intended to measure the perceptions of professionalism in Saudi medical students; such studies can help raise awareness among students, faculty and the administration of Saudi universities of the significance of professionalism to ensure standardised healthcare practices and contribute to the success of medical graduates. This study is among the few that have investigated professionalism among medical students in Saudi Arabia following the implementation of the SaudiMED framework to the new curriculum. ${ }^{29,30}$ Secondly, this study used a questionnaire with high internal consistency and whose tenets have been validated in the Arabian context. ${ }^{14}$ Finally, this instrument and/or the tenets of professionalism used by this instrument have been adapted to assess professionalism among medical students in other parts of the Arab region, Asia and elsewhere. ${ }^{19-21,26,27}$

This study had some limitations. The instrument had a very low internal consistency for the 'Accountability' subscale; overall, the items of this subscale were rated lowest by the survey participants. The reasons for these differences among subscales are not clear; however, social and cultural differences in how reprimand and punishment are perceived may contribute to lower accountability scores in this setting. Several studies on academic integrity among Saudi students have shown that some students tended to recommend more lenient sanctions. ${ }^{30,31}$ Thus, there is a need to strengthen the level of accountability during their training. Also, since professionalism is context-specific and culturally sensitive, there is a need to adapt the 'Accountability' subscale to fit the Arabic context. Future studies should consider refinements of the instrument to obtain better internal consistency for the 'Accountability' subscale.

\section{Conclusion}

This study found that medical students in the surveyed institution had high scores of professionalism. The findings of the present study could be used to improve the training of undergraduate medical students on professionalism. Future studies should assess the impact of the curriculum on the students' professionalism scores after adjusting for the effect of sociodemographic characteristics of the participants. Moreover, there is a need to explore the contextual issues affecting the subscales of professionalism according to the gender and level of education of the students and a longitudinal study is needed to assess the impact of the course curriculum on their levels of professionalism over time. 


\section{ACKNOWLEDGEMENTS}

Special thanks are extended to Dr. Mona Al-Sheikh, Associate Professor of Physiology and Head of Medical Education Department and Examination Center at Imam Abdulrahman Bin Faisal University, College of Medicine, for her leadership and support of this project.

\section{CONFLICT OF INTEREST}

The author declares no conflicts of interest.

\section{FUNDING}

No funding was received for this study.

\section{References}

1. Cruess R, Cruess S. Updating the Hippocratic Oath to include medicine's social contract. Med Educ 2014; 48:95-100. https:// doi.org.10.1111/medu.12277.

2. Batt-Rawden SA, Chisolm MS, Anton B, Flickinger TE. Teaching empathy to medical students: An updated, systematic review. Acad Med 2013; 88:1171-7. https://doi.org.10.1097/ ACM.0b013e318299f3e3.

3. Lehmann L, Sulmasy L, Desai S, ACP Ethics, Professionalism and Human Rights Committee. Hidden curricula, ethics, and professionalism: Optimizing clinical learning environments in becoming and being a physician: a position paper of the American college of physicians. Ann Intern Med 2018; 168:506-8. https://doi. org/10.7326/M17-2058.

4. Sethi A, Schofield S, McAleer S, Ajjawi R. The influence of postgraduate qualifications on educational identity formation of healthcare professionals. Adv Health Sci Educ Theory Pract 2018; 23:567-85. https://doi.org/10.1007/s10459-018-9814-5.

5. Brennan MD. The role of professionalism in clinical practice, medical education, biomedical research and health care administration. J Transl Int Med 2016; 4:64-5. https://doi.org/10.15 15/jtim-2016-0017

6. Birden H, Glass N, Wilson I, Harrison M, Usherwood T, Nass D. Teaching professionalism in medical education: A Best Evidence Medical Education (BEME) systematic review. BEME guide no. 25. Med Teach 2013; 35:e1252-66. https://doi.org/10 .3109/0142159X.2013.789132.

7. Guraya SY, Guraya SS, Almaramhy H. The legacy of teaching medical professionalism for promoting professional practice: a systematic review. Biomed Pharm J 2016; 9:809-17. https://doi. org $/ 10.13005 / \mathrm{bpj} / 1007$.

8. Al-Eraky MM. Twelve tips for teaching medical professionalism at all levels of medical education. Med Teach 2015; 37:1018-25. https://doi.org/10.3109/0142159X.2015.1020288.

9. Guraya SY, Guraya SS, Mahabbat NA, Fallatah KY, Al-Ahmadi BA, Alalawi $\mathrm{HH}$. The desired concept maps and goal setting for assessing professionalism in medicine. J Clin Diagn Res 2016; 10:JE01-5. https://doi.org/10.7860/JCDR/2016/19917.7832.

10. DeAngelis CD. Medical professionalism. JAMA 2015; 313:1837-8. https://doi.org/10.1001/jama.2015.3597.

11. Altirkawi K. Teaching professionalism in medicine: what, why and how? Sudan J Paediatr 2014; 14:31-8.
12. Birden H, Glass N, Wilson I, Harrison M, Usherwood T, Nass D. Defining professionalism in medical education: A systematic review. Med Teach 2014; 36:47-61. https://doi.org/10.3109/01 42159X.2014.850154.

13. Telmesani A, Zaini RG, Ghazi HO. Medical education in Saudi Arabia: A review of recent developments and future challenges. East Mediterr Health J 2011; 17:703-7.

14. Abdel-Razig S, Ibrahim H, Alameri H, Hamdy H, Haleeqa KA, Qayed KI, et al. Creating a framework for medical professionalism: An initial consensus statement from an Arab nation. J Grad Med Educ 2016; 8:165-72. https://doi.org/10.4300/ JGME-D-15-00310.1

15. American Board of Internal Medicine. Medical professionalism in the new millennium: The physicians charter. From: https:// abimfoundation.org/what-we-do/physician-charter Accessed: Aug 2020.

16. Abdulrahman M, Alsalehi S, Husain ZSM, Nair SC, Carrick FR. Professionalism among multicultural medical students in the United Arab Emirates. Med Edu Online 2017; 22:1372669. https://doi.org/10.1080/10872981.2017.1372669.

17. Tekian AS, Al Ahwal MS. Aligning the SaudiMED framework with the national commission for academic accreditation and assessment domains. Saudi Med J 2015; 36:1496-7. https://doi. org/10.15537/smj.2015.12.12916.

18. Chisholm MA, Cobb H, Duke L, McDuffie C, Kennedy WK. Development of an instrument to measure professionalism. Am J Pharm Educ 2006; 70:85. https://doi.org/10.5688/aj700485.

19. Nakamura M, Altshuler D, Chadwell M, Binienda J. Clinical skills development in student-run free clinic volunteers: a multi-trait, multi-measure study. BMC Med Educ 2014; 14:250. https://doi.org/10.1186/s12909-014-0250-9.

20. Bhutto SN, Asif M, Jawaid M. Professionalism among medical students at two public sector universities - A comparative study. J Postgrad Med Inst 2015; 29:3-8.

21. Akhund S, Shaikh ZA, Ali SA. Attitudes of Pakistani and Pakistani heritage medical students regarding professionalism at a medical college in Karachi, Pakistan. BMC Res Notes 2014; 7:150. https://doi.org/10.1186/1756-0500-7-150.

22. Chisholm-Burns MA, Spivey CA, Jaeger MC, Williams J, George C. Development of an instrument to measure pharmacy student attitudes toward social media professionalism. Am J Pharm Educ 2017; 81:65. https://doi.org/10.5688/ajpe81465.

23. Dubbai H, Adelstein B-A, Taylor S, Shulruf B. Definition of professionalism and tools for assessing professionalism in pharmacy practice: A systematic review. J Educ Eval Health Prof 2019; 16:22. https://doi.org/10.3352/jeehp.2019.16.22.

24. Shadid AM, Bin Abdulrahman AK, Bin Dahmash A, Aldayel AY, Alharbi MM, Alghamdi A, et al. SaudiMEDs and CanMEDs frameworks: similarities and differences. Adv Med Educ Pract 2019; 10:273-8. https://doi.org/10.2147/AMEP.S191705.

25. Li H, Ding N, Zhang Y, Liu Y, Wen D. Assessing medical professionalism: A systematic review of instruments and their measurement properties. PLOS One 2017; 12:e0177321. https://doi.org/1 0.1371/journal.pone.0177321.

26. Husain NE, Elsheikh NMA, Elsheikh MN, Mahmoud A, Sukkar MY, Ibnouf MAM, et al. Final year medical students and professionalism: lessons from six Sudanese medical schools? J Public Health Emerg 2018; 2:27. https://doi.org/10.21037/jphe.2018.08.01.

27. Sobani ZU, Mohyuddin MM, Syed AS, Farooq F, Qaiser KN, Gani F, et al. Professionalism in medical students at a private medical college in Karachi, Pakistan. J Pak Med Assoc 2013; 63:935-9. 
28. Seif-Farshad M, Bazmi S, Amiri F, Fattahi F, Kiani M. Knowledge of medical professionalism in medical students and physicians at Shahid Beheshti University of medical sciences and affiliated hospitals-Iran. Medicine 2016; 95:e5380. https://doi. org/10.1097/MD.0000000000005380.

29. Sattar K, Abdulghani HM, Meo SA, Soliman MM, Tauseef A, Irshad M, et al. Shaping medical professionalism in preclinical medical students: students perspective. Biomed Res 2017; 28:1001-5.
30. Al-Qahtani M, Roff S. Using the Dundee Polyprofessionalism Inventory I: Academic integrity to map student professionalism in 3 Arab Gulf countries. MedEdPublish 2017; 6:32. https://doi. org/10.15694/mep.2017.000201.

31. Sattar K, Roff S, Meo SA. Your professionalism is not my professionalism: Congruence and variance in the views of medical students and faculty about professionalism. BMC Med Educ 2016; 16:285-7. https://doi.org/10.1186/s129090160807-x. 